Article

\title{
How Schools Affected the COVID-19 Pandemic in Italy: Data Analysis for Lombardy Region, Campania Region, and Emilia Region
}

\author{
Davide Tosi ${ }^{1, *}$ and Alessandro Siro Campi ${ }^{2}$ (D) \\ 1 Department of Theoretical and Applied Sciences (DiSTA), University of Insubria, 21100 Varese, Italy \\ 2 Department of Electronics, Information and Bioengineering (DEIB), Politecnico Milano, 20133 Milano, Italy; \\ alessandro.campi@polimi.it \\ * Correspondence: davide.tosi@uninsubria.it
}

Citation: Tosi, D.; Campi, A.S. How Schools Affected the COVID-19 Pandemic in Italy: Data Analysis for Lombardy Region, Campania Region, and Emilia Region. Future Internet 2021, 13, 109. https://doi.org/ $10.3390 /$ fi13050109

Academic Editor: Michael Sheng

Received: 24 March 2021

Accepted: 26 April 2021

Published: 27 April 2021

Publisher's Note: MDPI stays neutral with regard to jurisdictional claims in published maps and institutional affiliations.

Copyright: () 2021 by the authors. Licensee MDPI, Basel, Switzerland. This article is an open access article distributed under the terms and conditions of the Creative Commons Attribution (CC BY) license (https:// creativecommons.org/licenses/by/ $4.0 /)$.

\begin{abstract}
Background: Coronavirus Disease 2019 (COVID-19) is the main discussed topic worldwide in 2020 and at the beginning of the Italian epidemic, scientists tried to understand the virus diffusion and the epidemic curve of positive cases with controversial findings and numbers. Objectives: In this paper, a data analytics study on the diffusion of COVID-19 in Lombardy Region and Campania Region is developed in order to identify the driver that sparked the second wave in Italy. Methods: Starting from all the available official data collected about the diffusion of COVID-19, we analyzed Google mobility data, school data and infection data for two big regions in Italy: Lombardy Region and Campania Region, which adopted two different approaches in opening and closing schools. To reinforce our findings, we also extended the analysis to the Emilia Romagna Region. Results: The paper shows how different policies adopted in school opening/closing may have had an impact on the COVID-19 spread, while other factors related to citizen mobility did not affect the second Italian wave. Conclusions: The paper shows that a clear correlation exists between the school contagion and the subsequent temporal overall contagion in a geographical area. Moreover, it is clear that highly populated provinces have the greatest spread of the virus.
\end{abstract}

Keywords: COVID-19; SARS-CoV-2; data analytics; schools' impact; Google mobility impact

\section{Introduction}

Data analysis [1-3] has proved to be of fundamental importance for studying and predicting the behavior of the pandemic of SARS-CoV2 and COVID-19, in order to intervene promptly and stem its spread [4-6]. The school opening has been a hotly debated topic nationwide and worldwide [7-9], with at one side scientists that consider schools safe and on the other side scientists who consider schools unsafe and unsecured. In our opinion, school is not a safe environment by definition, but it must be made safe taking serious actions with rigorous protocols and structural interventions as described in [10,11]. Effects of schools opening and the propagation of COVID-19 are described in other countries, such as in [12] where the effects of school openings on hospitalization in USA are modeled, or in [11] where the authors explain how UK schools are causing COVID-19 spreading and how to act to reduce their impact.

The data (shown in Table 1) on the growth of infections by age groups from the beginning of September to March that are published weekly in the epidemiological reports of the ISS (Istituto Superiore Sanità) [www.iss.it] (accessed on 27 April 2021), indicate that the age group 0-9 have had a growth between 6 and 10 times higher than all other ages. (Please note that following the ISS indication, under $<19$ young population are mostly asymptomatic with a percentage of $75 \%$. Hence, the ratio of these cases in the younger population is probably much higher than in the elder population.) 
Table 1. The trend of infections between 29 December 2020 and 10 March 2021.

\begin{tabular}{cccc}
\hline Age & $\begin{array}{c}\text { Number of Cases } \\
\mathbf{1 2 / 2 9 / 2 0 2 0}\end{array}$ & $\begin{array}{c}\text { Number of Cases } \\
\mathbf{3 / 1 0 / 2 0 2 1}\end{array}$ & Percentage Growth \\
\hline $0-9$ & 78,664 & 144,301 & 83.44 \\
\hline $10-19$ & 170,048 & 277,785 & 63.36 \\
\hline $20-29$ & 245,458 & 367,308 & 49.64 \\
\hline $30-39$ & 251,226 & 382,754 & 52.35 \\
\hline $40-49$ & 326,571 & 494,423 & 51.40 \\
\hline $50-59$ & 368,635 & 545,225 & 47.90 \\
\hline $60-69$ & 229,200 & 344,498 & 50.30 \\
\hline $70-79$ & 172,071 & 255,511 & 48.49 \\
\hline $80-89$ & 149,953 & 209,503 & 39.71 \\
\hline
\end{tabular}

The data show that from 29 December 2020 to 10 March 2021, the infections increased by $83.44 \%$ in the age group between 0 and 9 years. Additionally, $63.55 \%$ in the $10-19$ age range. The school age is therefore the one where the contagion has grown a little more. The third group for growth is the one between 30 and 39 years, with $52.35 \%$ and almost all the other age groups are below $50 \%$ growth. The older age groups registered the lowest percentage growth: between the ages of 80 and 89 , the contagion grew by $39.71 \%$ over the period, and over 90 years even less $31.28 \%$. These data disprove the idea that the problem was that of transport, which essentially concerned the high schools (the youngest ones mostly go to school on foot or are accompanied by their parents by private means).

Looking at the data and statements of neighboring countries and with demographic characteristics similar to ours, the situation is already well defined on how much schools are drivers of contagion:

- In France schools and universities have been indicated as the first factor in active outbreaks [source: Sante Publique France];

- In the UK, primary and secondary school, after careful tracing, was in third place as number of reports [source: NHS Test and Trace UK];

- In Germany, the school was recently declared to be at high risk in some statements made by A. Merkel herself in early February 2021;

- Several papers (recently appeared in the Lancet, Nature and Science), albeit with all the stated limits in the works, show that the closure of schools is the second most impacting factor, as NPI (Non-Pharmaceutical Interventions), on the reduction of the contagiousness index Rt [13,14];

- Further preliminary analyses have been carried out on the Piedmonts Region and national territory by researcher A. Ferretti and a clear relation on the increase of cases and the school opening is reported [15];

- The Lazio Region was driven to an emergency state due to school contagion impact [16];

- During the 19 March 2021 Press Conference, the Belgium Prime Minister said: "From contact analyses, we can also see that schools are key places where many infections happen," De Croo said. "Children are infected there, take the virus home, possibly infect their parents, who may infect their colleagues if they are still going to work, and so the chain continues" [17];

- We also remind you that $75 \%$ of the positives in the youth age group under 19 are asymptomatic, therefore, are unaware carriers of the virus within family walls [source ISS];

- In the week of mid-February 2021 alone, we collected more than 50 newspaper articles (headings national and local) that highlight outbreaks in Italian schools [18]; 
- Recent statements by the ISS (Higher Institute of Health) Director G. Rezza, dated 26 February 2021, highlight the problem of numerous outbreaks in Italian schools.

We believe the distinction between the school environment per se or extended to include the public transport and the dynamics of entering/leaving the school has no meaning. At the moment, the main contribution of the school to viral circulation must be analyzed and quantitatively assessed.

Obviously, it remains of fundamental importance to determine what risks are exposed to children with school closures, which certainly impacts on mental health, cognitive development and which are fundamental in developmental age and, consequently, arrive at risk-weighted decisions, as described in [19-21] where the authors highlight the psychological impact school closures may have on young people.

At the end of August, we presented a predictive model to show how the second wave in Italy was practically already started. The model estimated a relative peak around the $7 / 8$ of September and then a slight decline in slowdown waiting to see the strong impact, within two weeks, coming from the schools reopening (on 14 September). If there now we look back (see Figure 1), we clearly observe that the exponential explosion of the contagion in Italy started exactly on 28 September, so exactly two weeks after the reopening of the Italian schools.

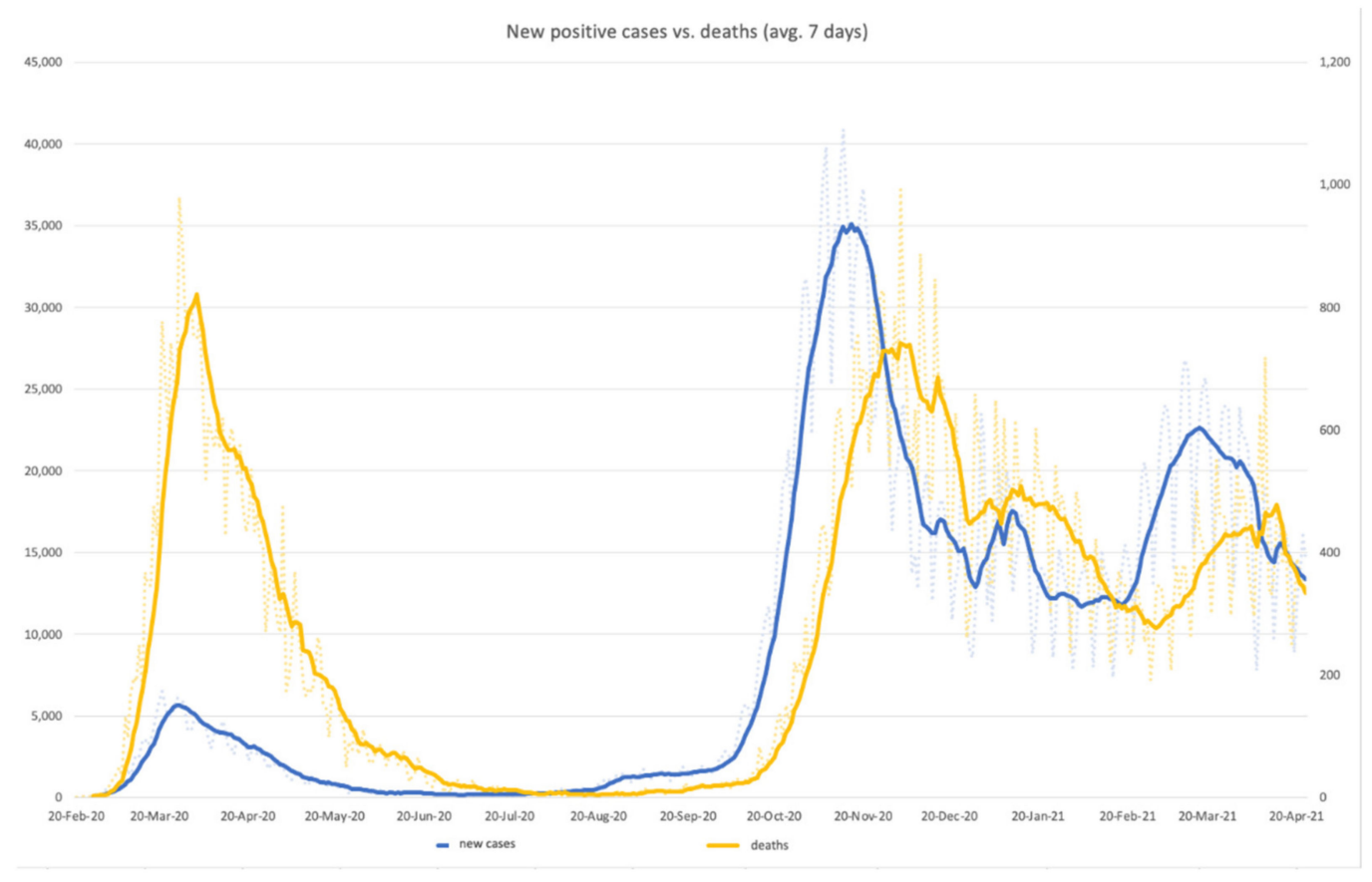

Figure 1. Observed real curves for new daily cases and deaths in Italy.

Our model was based on the hypothesis that schools are an important driver of contagion. Furthermore, the major impact is to be considered in the contagion that then happens at a second layer inside the family context, leading after about two incubation cycles of the virus. This explains why we used a time lag of 14 days, in our predictive model. Even if it is not our aim to "blame" children or teachers for these infections and we watched the school operators doing their utmost in the summer to find solutions to secure the school environment as much as possible, we cannot be blind and avoid seeing that the virus finds fertile ground for contagion in closed environments, very populated, poorly ventilated, as are our school environments which are not among the most modern in Europe. Therefore, to think that the school is a safe environment, by definition, is wrong because it has caused and will be the cause of uncontrolled virus spread. 
In this paper, we want to analyze the few official MIUR (Ministry of Instruction, University and Research) data available on contagion at schools, to understand whether and how much the school may have impacted on the territorial contagion.

\section{Materials and Methods}

In December, the MIUR published an official dataset relating to infections in schools (joining different data collection) for the period 14 September 2020-30 October 2020 [22]. The report spoke of approximately 65,000 Italian positive cases identified in the time window 14 September-30 October (we are only talking about primary and lower secondary school, because most of the high schools were in any case remote). The available data count 65,000 cases for the whole Italy, but they are underestimated because not all Italian schools have participated in this tracking activity, and not all schools have released their data to the ministry. It should also be considered that $75 \%$ of those under 19 years old are asymptomatic [www.iss.it] (accessed on 27 April 2021), and this large slice of young people is lost in the tracing activity. In total, 65,000 cases out of 360,000 total cases [23,24] detected in the same period is a considerable percentage of $18 \%$ of the total. Furthermore, the major impact is to be considered in the contagion that then arose in the second instance within the family walls, leading after about two incubation cycles of the virus, to an uncontrolled growth of the curves (the one that we observed from 28 September 2020 onwards in our predictive model and in Figure 1).

In order to understand the relation between schools and global infection, we considered the data officially released by the MIUR and we carried out a correlation analysis on the Lombardy Region (RL) and Campania Region (RC), two regions that have adopted two different policies of opening and closing schools. RL is characterized by 12 provinces for a total of $10 \mathrm{M}$ inhabitants, while RC has 5 provinces with $5.8 \mathrm{M}$ inhabitants. Moreover, we extended this analysis to a third Italian region: Emilia Romagna Region (REm) that is characterized by 9 provinces and a total population of $4.5 \mathrm{M}$ inhabitants. At the end, the study covered 24 provinces out of 107 Italian provinces, and 20.3 M inhabitants out of $60.3 \mathrm{M}$ total Italian inhabitants.

The three regions applied the following opening/closure strategies:

- $\quad$ RL reopened all primary and secondary schools in presence at 14 September 2020 (high level secondary school with 50\% attendance and 50\% online) [25];

- $\quad \mathrm{RC}$ reopened all primary and secondary schools in presence at 24 September 2020 (high level secondary school with 50\% attendance and 50\% online) and then all levels were closed in advance starting from the October 16 and until 13 November [26];

- REm reopened all primary and secondary schools in presence at 14 September 2020 (high level secondary school with 50\% attendance and 50\% online).

Specifically, a twofold correlation study was conducted:

1. between school contagion index (both total and separate for primary and secondary school, respectively) and an index of global contagion at the provincial level (both for RL and RC). The correlation study was done with a global contagion index on the reference period from 14 September 2020 to 30 October 2020 and also considering the first two weeks after the reopening of schools (from 14 September to 28 September, where the contagion theoretically should not be detectable, given the latency time between positivity and the onset of symptoms and related diagnostic screening) then in the following two weeks (from 28 September to 12 October, when it is likely that contagion was triggered in schools and then it potentially spreads in the intrafamily context), and after four weeks of spreading;

2. between contagion index and mobility indexes derived from the COVID-19 Google Community Mobility Report [27], where mobility data at regional and national level in different sectors (e.g., mobility near parks and public gardens, pharmacies, at work level, train stations, residential, etc.) were analyzed. 
We computed the correlation index by using the Pearson correlation index (CI), as:

$$
\text { correl_index }(\mathrm{x}, \mathrm{y})=\frac{\sum(x-\bar{x})(y-\bar{y})}{\sqrt{\sum(x-\bar{x})^{2} \sum(y-\bar{y})^{2}}}
$$

F-Test was then conducted on the dataset to determine if there is a significant difference between the means of two groups and to understand the statistical significance of our findings. Linear regression models and the $\mathrm{R}^{2}$ coefficient of determination were also discussed.

Summarizing, all the datasets used in this study are:

- Official Positive Cases at Italian Schools released by MIUR Ministry [22];

- Official Positive Cases in Italy by Department of Civil Protection [24];

- Rt Dataset by University of Insubria [23];

- Mobility Data by Google Community [27].

\section{Results}

\subsection{Comparing Lombardy, Campania and Emilia Romagna Contagion Indexes}

As for the Lombardy Region (RL), the identified cases are 13,967 out of 88,412 total cases $(15.8 \%)$, in the reference period September 14th-October 30th. In the Campania Region (RC), the cases identified are 4620 about 42,815 total cases (10.8\%). It is important to recall that the Lombardy Region and the Campania Region have used in October different school policies, the first leaving primary and secondary schools open in attendance and high secondary schools at 50\% in attendance [25], while RC intervening instead with targeted closures: schools opened at September 24 (secondary schools at 50\% in attendance), and then all levels were closed in advance starting from the October 16 and until November 13 [26].

Let us now focus on the data of the Lombardy Region at the provincial level (see Figure 2 for numerical details for all the RL provinces: VA Varese, SO Sondrio, PV Pavia, MN Mantova, MI Milan, MB Monza and Brianza, LO Lodi, LC Lecco, CR Cremona, CO Como, BS Brescia, and BG Bergamo). If we calculate a "school contagion" index and a "global contagion" index (normalized on the ISTAT2020 population [http:/ / demo.istat.it] (accessed on 27 April 2021), for each province as: cases/1000 inhabitants), it is interesting to note that there is a strong correlation between a high rate of contagion in school and high contagion rate then at the provincial level. This correlation is not found instead by looking at, for example, the population density as another variable. As an example, let us take the case of Varese (VA): VA was one of the Lombardy provinces that was mostly impacted by the second COVID-19 wave. VA has the highest school contagion rate (together with MB) and a very high global contagion rate, as depicted in Figure 2.

Let us now consider what happened in the first two weeks after the school reopening (14 September-28 September) where theoretically the effects of the school were just beginning to be visible: it is noted how there is no correlation between the school contagion index and the global contagion index at two weeks $(\mathrm{CI}=-0.10)$. If, on the other hand, we look at the correlation between school contagion and the index of contagion two weeks after the reopening of schools, we have a clear correlation with $\mathrm{CI}=0.69$, which rises further considering the effect after four weeks with $\mathrm{CI}=0.80$. For the entire reference period the $\mathrm{CI}$ rises to $\mathrm{CI}=0.89$ ) as clearly depicted in the scatter plot of Figure 3 (the linear regression trend line as the $R^{2}$ coefficient of determination with a very high value $R^{2}=0.94$ ). The correlation indices are identical if the school contagion data is separated between primary and secondary school. It is interesting to observe the correlation between the contagion index and the population density $(\mathrm{CI}=0.60)$ but not between the school index and the population density $(\mathrm{CI}=0.37)$. If, on the other hand, we observe the correlation between the contagion index and the mobility indexes, we note that the lower mobility registered with government restrictions and DPCM (Decreto del Presidente del consiglio dei ministri) does not have an interdependence relation with the contagion more or less accentuated 
in the various provinces of RL, with the exception of transit station mobility that shows a correlation $\mathrm{CI}=-0.57$.

\begin{tabular}{|c|c|c|c|c|c|c|c|}
\hline & School index & $\begin{array}{l}\text { (cases/1000 pop.) } \\
\text { Primary School index }\end{array}$ & Secondary School index & $\begin{array}{l}\text { (sept. 14 to oct. 30) } \\
\text { Contagion index }\end{array}$ & $\begin{array}{l}\text { (sept. } 14 \text { to sept. 28) } \\
\text { Contagion index first } 2 \text { weeks }\end{array}$ & $\begin{array}{c}\text { (sept. } 28 \text { to oct. 12) } \\
\text { Contagion index after } 2 \text { weeks }\end{array}$ & $\begin{array}{c}\text { (oct. } 12 \text { to oct. 26) } \\
\text { Contagion index after } 4 \text { weeks }\end{array}$ \\
\hline VA & 2.6 & 1.7 & 0.9 & 11.2 & 0.24 & 0.69 & 4.57 \\
\hline so & 1.2 & 0.8 & 0.4 & 6.5 & 0.14 & 0.55 & 2.62 \\
\hline $\mathbf{P V}$ & 0.7 & 0.5 & 0.2 & 7.7 & 0.41 & 0.76 & 3.66 \\
\hline MN & 0.7 & 0.5 & 0.2 & 4.1 & 0.16 & 0.37 & 1.84 \\
\hline MI & 1.7 & 1.0 & 0.6 & 12.8 & 0.34 & 1.04 & 6.64 \\
\hline MB & 2.7 & 2.0 & 0.8 & 13.1 & 0.08 & 0.96 & 5.82 \\
\hline to & 1.1 & 0.8 & 0.3 & 6.9 & 0.20 & 0.43 & 3.69 \\
\hline LC & 1.2 & 0.7 & 0.5 & 6.5 & 0.13 & 0.44 & 3.04 \\
\hline CR & 0.7 & 0.4 & 0.3 & 4.7 & 0.08 & 0.37 & 2.18 \\
\hline co & 1.5 & 1.1 & 0.4 & 8.6 & 0.12 & 0.45 & 3.74 \\
\hline BS & 0.4 & 0.3 & 0.1 & 3.5 & 0.23 & 0.39 & 1.58 \\
\hline$B G$ & 0.4 & 0.3 & 0.1 & 2.5 & 0.15 & 0.32 & 1.02 \\
\hline
\end{tabular}

\begin{tabular}{|c|c|c|c|c|c|}
\hline Parks Mobility & \multicolumn{2}{|r|}{ (sept. 1 to oct. 15 - avg value) } & Transit Station Mobility & Population ISTAT 2020 & Pop. Density (pop./kmq \\
\hline & 20.38 & -10.48 & -35.80 & 892532 & 744.95 \\
\hline & 19.33 & -15.98 & -21.51 & 180941 & 56.62 \\
\hline & 14.66 & -7.00 & -27.07 & 546515 & 184.1 \\
\hline & 32.81 & -10.96 & -12.87 & 411062 & 175.56 \\
\hline & 19.39 & -20.76 & -32.09 & 3279944 & 2081.64 \\
\hline & 33.41 & -11.52 & -23.50 & 878267 & 405.41 \\
\hline & -2.25 & -1.54 & -20.07 & 230607 & 294.52 \\
\hline & 38.42 & -5.37 & -8.17 & 337087 & 418.42 \\
\hline & 19.28 & -10.70 & -16.35 & 358347 & 202.4 \\
\hline & 76.89 & -9.96 & -6.78 & 603828 & 472.1 \\
\hline & 80.13 & -8.67 & -6.85 & 1268455 & 265.06 \\
\hline & 33.67 & -12.04 & -22.30 & 1116384 & 405.24 \\
\hline
\end{tabular}

\begin{tabular}{|c|c|c|c|c|}
\hline & Corr. Index & (8) & 0.89 & school index vs. contagion index \\
\hline & Corr. Index & (8) & 0.88 & primary school index vs. contagion index \\
\hline LOMBARDY REGION & Corr. Index & (2) & 0.87 & secondary school index vs. contagion index \\
\hline \multirow[t]{8}{*}{ (school opening sept. 14) } & Corr. Index & 0 & -0.10 & school index vs. contagion index first 2 weeks \\
\hline & Corr. Index & 0 & 0.69 & school index vs. contagion index after 2 weeks \\
\hline & Corr. Index & (2) & 0.80 & school index vs. contagion index after 4 weeks \\
\hline & Corr. Index & $\otimes$ & 0.60 & pop. density vs. contagion index \\
\hline & Corr. Index & 0 & -0.21 & contagion index vs. Parks mobility \\
\hline & Corr. Index & 0 & -0.32 & contagion index vs. Retail mobility \\
\hline & Corr. Index & 0 & -0.57 & contagion index vs. Transit station mobility \\
\hline & Corr. Index & (1) & 0.37 & school index vs. pop. density \\
\hline
\end{tabular}

Figure 2. Lombardy Region data set for school contagion index and overall contagion. Correlation study.

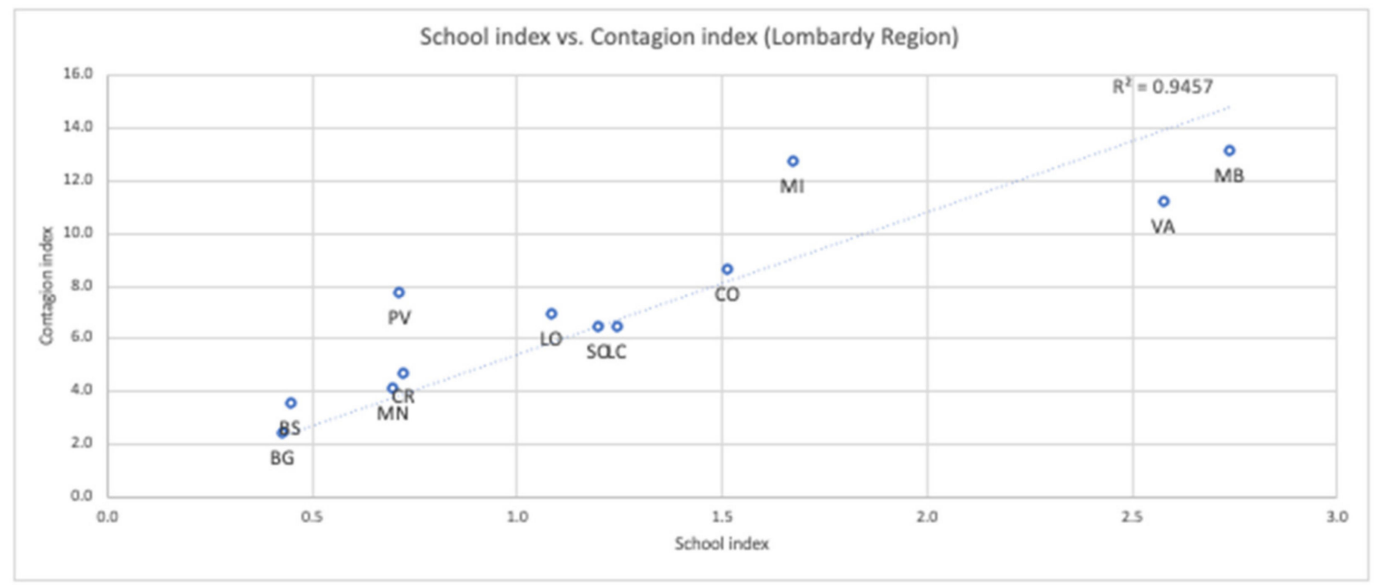

Figure 3. Lombardy Region scatter plot for school contagion index vs. overall contagion index.

Since the number of datapoints is limited, we tested the statistical significance with F-Test $(\alpha=0.05)$ and we obtained the following values: $\mathrm{F}=21.20$ with a $\mathrm{P}(\mathrm{F})=7.94 \times 10^{-6}$ and an F critical $=2.82(\mathrm{gdl}=11)$, so the null hypothesis is rejected (since F calculated is greater than the $\mathrm{F}$ critical).

As for Campania Region (Figure 4) and its five provinces (SA Salerno, NA Napoli, CE Caserta, BN Benevento, AV Avellino), schools reopened two weeks later than RL and 
were closed in advance, starting from 16 October and until 13 November. We observed the following statistical behavior between the contagion variables in the schools and the subsequent contagion in the regional provinces: in the first few days after the schools re-opening (28 September to 12 October) the correlation index is equal to $\mathrm{CI}=0.51$ and then increased after two more additional weeks to the strong value $\mathrm{CI}=0.93$ (i.e., showing the clear impact of schools reopening). The global correlation index is equal to $\mathrm{CI}=0.47$, with a behavior that is in line with the one observed for Lombardy Region. There is only a temporal shift ahead, since RC reopened schools two weeks later than RL. Moreover, also for $\mathrm{RC}$, a strong correlation exists between the contagion index and the population density $(\mathrm{CI}=0.74)$. As for mobility data, a strong correlation index is detected only between the contagion index and the retail and recreation mobility $(C I=0.86)$, thus suggesting that this mobility factor may have had an impact to the spread of COVID-19, too.
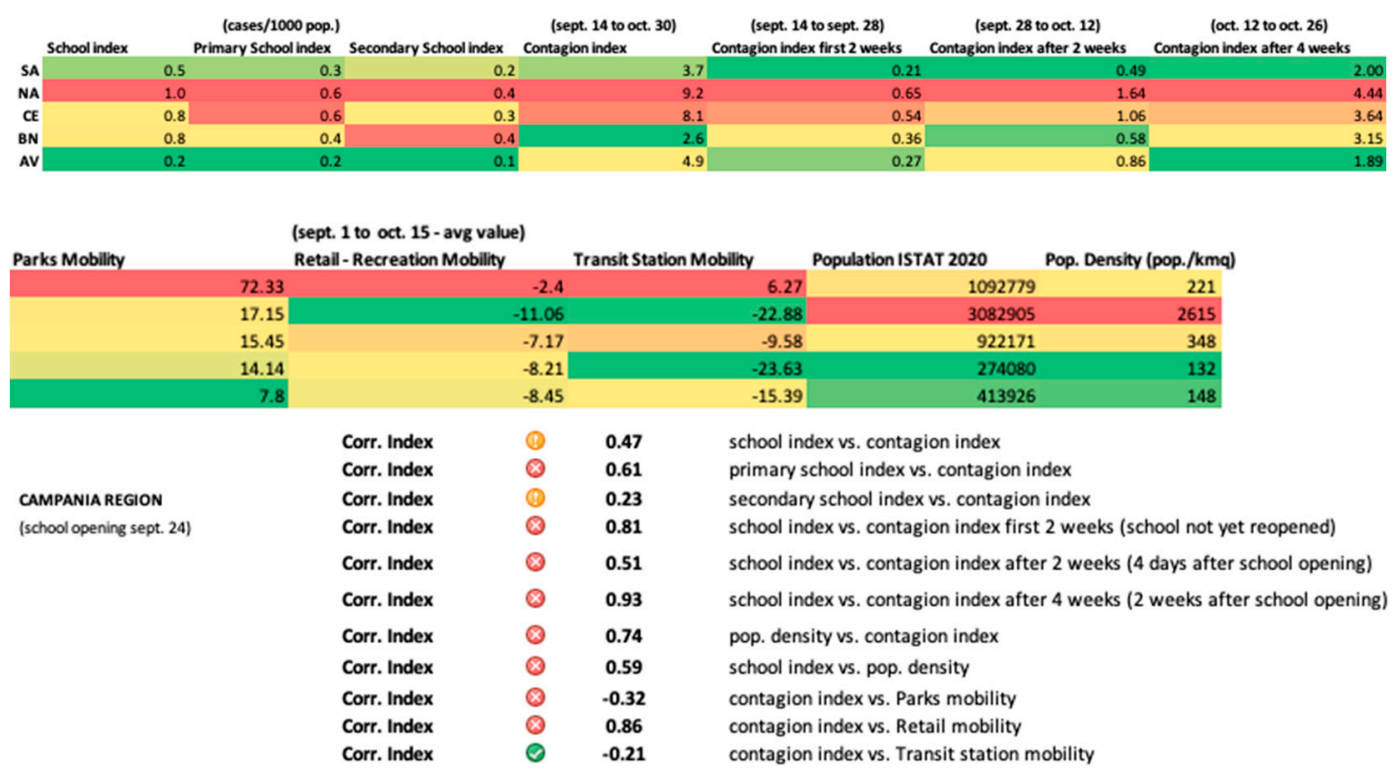

Figure 4. Campania Region data set for school contagion index and overall contagion. Correlation study.

To reinforce our findings, we extended our analysis evaluating also the Emilia Romagna Region and its nine provinces (BO-Bologna, FC—Forlì-Cesena, FE-Ferrara, MOModena, PC—Piacenza, PR—Parma, RA—Ravenna, RE—Reggio Emilia, RN—Rimini). For this region, the identified cases are 3050 out of 19,670 total cases $(15.5 \%)$, in the reference period 14 September-30 October, with a similar \% to RL. Moreover, REm followed an opening/closure strategy such as the one applied to RL. As depicted in Figures 5 and 6, correlation between the school contagion index and the overall contagion index per each province increases over time, starting from an inverse correlation at the beginning of school reopening $\mathrm{CI}=-0.50$ to an index of $\mathrm{CI}=0.41$ after two weeks, and $\mathrm{CI}=0.69$ after four weeks since school reopening. The index for the overall period is $\mathrm{CI}=0.76$ with the secondary school impacting more than the primary school $(\mathrm{CI}=0.86 \mathrm{vs} . \mathrm{CI}=0.58)$. Hence, also in this case, the detected behavior is consistent with the one observed in RL and RC.

Since the number of datapoints is limited, we tested the statistical significance with F-Test $(\alpha=0.05)$ and we obtained the following values: $\mathrm{F}=23.16$ with a $\mathrm{P}(\mathrm{F})=9.27 \times 10^{-5}$ and an F critical $=3.43(\mathrm{gdl}=8)$, so the null hypothesis is rejected (since F calculated is greater than the $\mathrm{F}$ critical). 


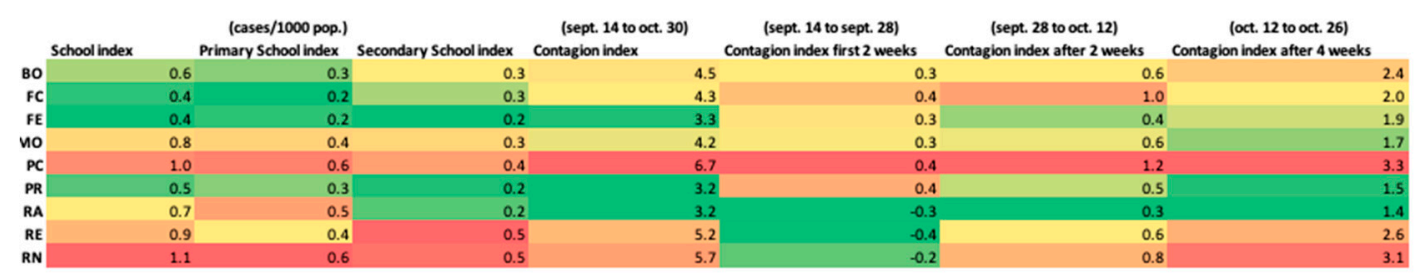

\begin{tabular}{|c|c|c|c|c|}
\hline & Corr. Index & (2) & 0.76 & school index vs. contagion index \\
\hline & Corr. Index & (2) & 0.58 & primary school index vs. contagion index \\
\hline & Corr. Index & (2) & 0.86 & secondary school index vs. contagion index \\
\hline EMILA ROMAGNA REGION & Corr. Index & 0 & -0.50 & school index vs. contagion index first 2 weeks \\
\hline \multirow[t]{4}{*}{ (school opening sept. 14) } & Corr. Index & 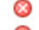 & 0.41 & school index vs. contagion index after 2 weeks \\
\hline & Corr. Index & Q & 0.69 & school index vs. contagion index after 4 weeks \\
\hline & Corr. Index & (2) & 0.53 & school index vs. pop. density \\
\hline & Corr. Index & $\otimes$ & 0.23 & pop. density vs. contagion index \\
\hline
\end{tabular}

Figure 5. Emilia Romagna Region data set for school contagion index and overall contagion. Correlation study.

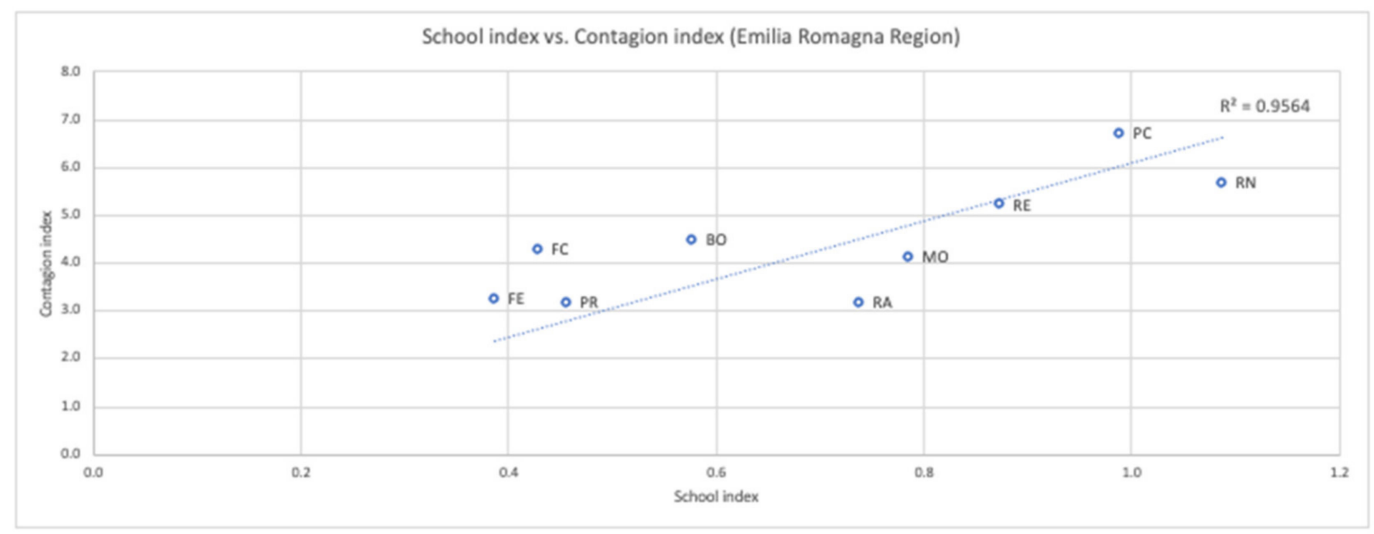

Figure 6. Emilia Romagna scatter plot for school contagion index vs. overall contagion index.

\subsection{Reproduction Number (Rt) and Contagion Curves Evaluation}

If we take also a look at the contagion curve (new daily positive cases), see Figure 7, $\mathrm{RC}$, which was the region that applied the more restrictive policies for schools, was able to invert the trend of new daily positive cases earlier than the other two regions. Moreover, it is interesting to observe that also the ascent trend was less steep than for RL and REm, with the average doubling time (in the number of positive cases) equal to 8 days (3.4 days for RL and 6 days for REm).

Moreover, we computed the Rt (reproduction number) for all the Italian regions [23]. The Rt estimation was conducted by using the Time-Dependent method by Wallinga and Teunis [28] with a time aggregation level equal to 10 days, to understand the impact of schools reopening on the Rt trend. All regional and provincial trends are reported in our web site: www.covid19-italy.it (accessed on 27 April 2021). The trend is depicted in Figure 8: it is clear that RC was able to contain the reproduction number to a low peak value $\mathrm{Rt}=1.1$ while REm and RL have higher peak values of $\mathrm{Rt}=1.4$ and $\mathrm{Rt}=1.5$, respectively. Moreover, $\mathrm{RC}$ was the first one to reach the guard value $\mathrm{Rt}=1.0$ (9 November2020) probably due to the prompt school closures. In Table 2, we also summarize for all the Italian regions (categorized by the date of school opening) the dates when the Rt peak is reached and the associated Rt value. The average Rt value is also reported for the regions that opened schools at 14 September 2020 and the ones that opened schools later at 24 September 2020. Regions that postponed the schools' opening had an average Rt lower than the one registered for regions that opened schools earlier: $\mathrm{Rt}=1.27 \mathrm{vs}$. $\mathrm{Rt}=1.46$, respectively. The Campania region that applied the most stringent policies in Italy, by closing all schools promptly, registered the lowest Rt value among all the Italian regions. Moreover, we can observe that regions that opened schools earlier had their Rt peaks earlier than regions that postponed the schools' reopening: in the first category (14 September), eight regions had 
their Rt peak at 10 October 2020 and five regions at 20 October 2020; in the second category (24 September), six regions had their Rt peak at 20 October 2020 and only one region at 10 October, thus suggesting that the impact of school reopening is actually detected after two weeks, as expected.

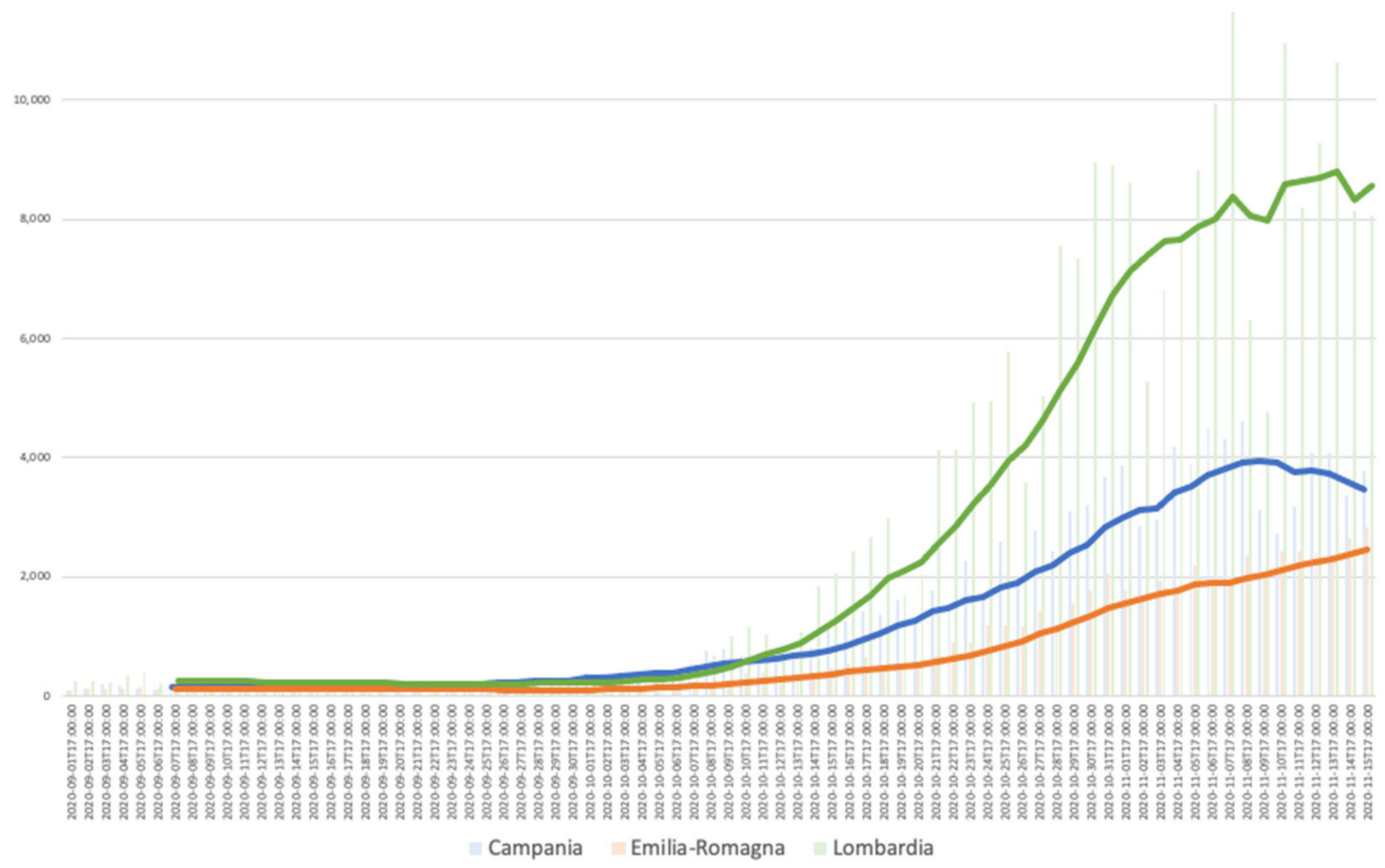

Figure 7. Daily positive new cases and 7-days avg. trend for the Italian regions: Campania, Emilia and Lombardy in the time frame 1 September 2020 to 15 November 2020.
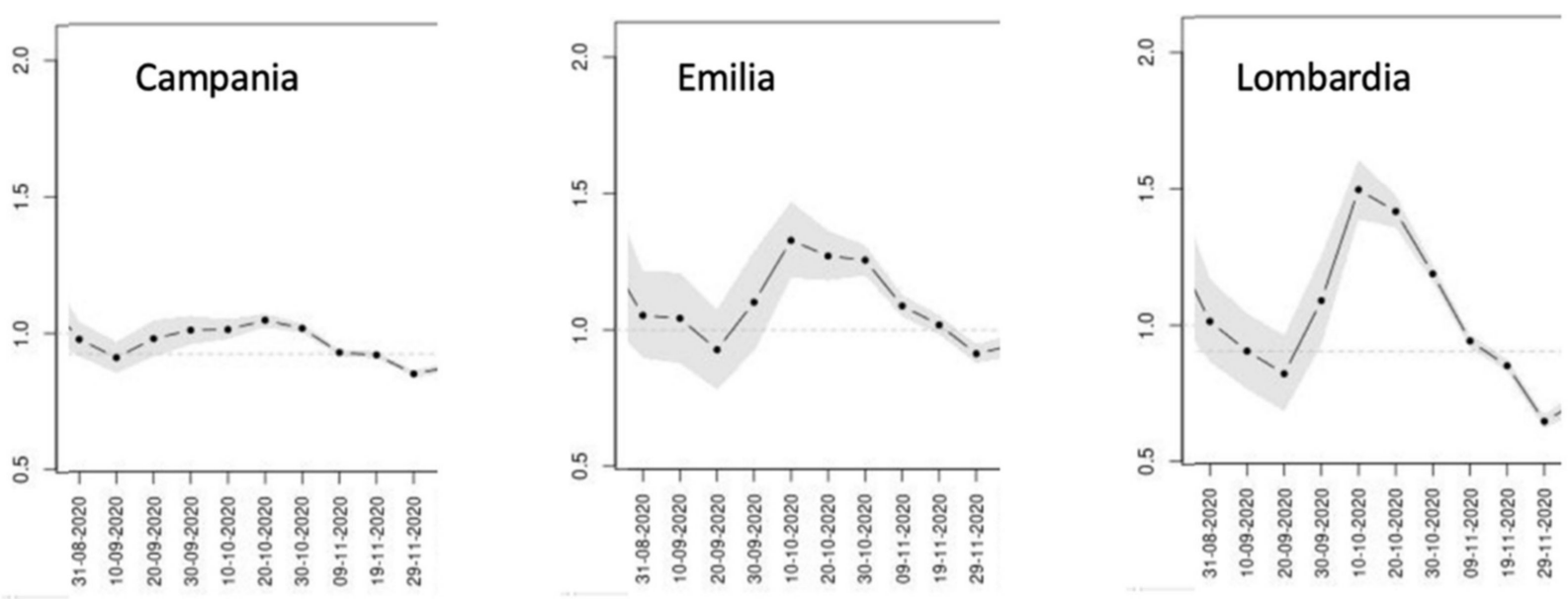

Figure 8. Rt trend for the three Italian regions: Campania, Emilia and Lombardy. 
Table 2. Rt peak values and dates associated to Italian Regions.

\begin{tabular}{|c|c|c|c|c|c|}
\hline \multicolumn{3}{|c|}{14 September 2020} & \multicolumn{3}{|c|}{24 September 2020} \\
\hline & Rt Peak Date & Rt Peak Value & & Rt Peak Date & Rt Peak Value \\
\hline Emilia & $10 / 10 / 2020$ & 1.4 & Abruzzo & $10 / 10 / 2020$ & 1.3 \\
\hline Lazio & $10 / 20 / 2020$ & 1.4 & Basilicata & $10 / 20 / 2020$ & 1.4 \\
\hline Liguria & $10 / 10 / 2020$ & 1.4 & Calabria & $10 / 20 / 2020$ & 1.4 \\
\hline Lombardia & $10 / 10 / 2020$ & 1.5 & Campania & $10 / 20 / 2020$ & 1.1 \\
\hline Marche & $10 / 20 / 2020$ & 1.4 & Friuli * & $10 / 20 / 2020$ & 1.3 \\
\hline Molise & $10 / 10 / 2020$ & 1.8 & Puglia & $10 / 20 / 2020$ & 1.2 \\
\hline Piemonte & $10 / 20 / 2020$ & 1.5 & Sardegna * & $10 / 20 / 2020$ & 1.2 \\
\hline Sicilia & $10 / 10 / 2020$ & 1.3 & & & \\
\hline Toscana & $10 / 10 / 2020$ & 1.4 & & & \\
\hline Trento & $10 / 20 / 2020$ & 1.5 & & & \\
\hline Umbria & $10 / 10 / 2020$ & 1.4 & & & \\
\hline Valle d'Aosta & $10 / 10 / 2020$ & 1.6 & & & \\
\hline \multirow[t]{2}{*}{ Veneto } & $10 / 20 / 2020$ & 1.4 & & & \\
\hline & Avg. & 1.46 & & Avg. & 1.27 \\
\hline
\end{tabular}

* Friuli schools opening 16 September 2020. Sardegna schools opening 22 September 2020.

\section{Discussion}

Our work shows that the schools' reopening had a clear impact on the overall contagion, since all the three analyzed regions had an increase in the number of cases two weeks after the schools' reopening. The time-lag detected for all the analyzed provinces is equal to 14 days, confirming our hypothesis that two incubation cycles are needed to perceive the impact of the contagion coming from schools. Moreover, the provinces that have had a large number of cases in the school environment are the ones that have subsequently had a higher total number of cases, and as expected, the contagion increased over time. The most significant example is Varese that with reference to the other provinces of the Lombardy Region is the one that had the highest incidence in schools' spreading over time throughout the entire provincial territory, thus leading to one of the most affected provinces in Italy during the second COVID-19 wave. Our study also suggests that population density is another driver of contagion by favoring the virus spread, while the mobility of population (that was already drastically reduced by the governmental restrictions with respect to the normal baseline) did not impact the COVID-19 spread.

Promptly acting by closing the schools (as in the case of RC) was able to contain the COVID-19 spread (i.e., as listed in Table 2, RC was the region with the lowest Rt peak, and it was able to invert the trend of new daily cases before the other two regions RL and REm, as depicted in Figure 7).

It is also interesting to observe, as reported in Table 3, that RL had the highest school contagion index and the highest overall contagion index, while REm had the lowest overall contagion index despite having the same school index of RC. This can be explained by the impact the retail and recreation mobility may have had for RC. 
Table 3. Summary contagion findings.

\begin{tabular}{cccc}
\hline & School Index & Contagion Index & Rt \\
\hline & (Max-Min-Avg) & (Max-Min-Avg) & (Peak) \\
Lombardy Region & 2.7 & 13.1 & \\
& 0.4 & 2.5 & \\
\hline \multirow{3}{*}{ Campania Region } & 1.3 & 7.4 & \multirow{2}{*}{1.1} \\
& 1.0 & 9.2 & \\
\hline \multirow{2}{*}{ Emilia Region } & 0.2 & 2.6 & 1.4 \\
& 0.7 & 5.9 & \\
\hline
\end{tabular}

\section{Conclusions}

There are different elements and different factors that suggest us to conclude that the school is not a safe environment by definition, but it must be made sure, by taking serious actions to protect students, teachers, and operators who work and live every day the school context, such as strict personal hygienic conditions, respect for the rules, serious contact tracing activities, timely testing and swabs for students, adequate natural and artificial ventilation of classrooms, etc.

This study may be extended to other Italian regions and to new data, when the MIUR will officially release new data on the infection detected within the schools.

Author Contributions: Conceptualization, D.T. and A.S.C.; Methodology, D.T. and A.S.C.; Software, D.T.; Validation, D.T. and A.S.C.; Formal Analysis, D.T.; Investigation, D.T. and A.S.C.; Data Curation, D.T.; Writing D.T. and A.S.C.; Funding Acquisition, D.T. All authors have read and agreed to the published version of the manuscript.

Funding: This research is partially funded by the ERC Advanced Grant project 693174 GeCo (DataDriven Genomic Computing), 2016-2021.

Institutional Review Board Statement: Not applicable.

Informed Consent Statement: Not applicable.

Data Availability Statement: Contagion Dataset are available in open format at the GitHub of the Italian Department Civil Protection: https:/ / github.com/pcm-dpc/COVID-19 (accessed on 27 April 2021).

Conflicts of Interest: The authors declare no conflict of interest.

\section{References}

1. Tosi, D. Cell Phone Big Data to Compute Mobility Scenarios for Future Smart Cities. Int. J. Data Sci. Anal. 2018, 4, 265-284. [CrossRef]

2. Tosi, D.; LaRosa, M.; Marzorati, S.; Dondossola, G.; Terruggia, R. Big Data from Cellular Networks: How to Estimate Energy Demand at real-time. In Proceedings of the IEEE International Conference on Data Science and Advanced Analytics (DSAA 2015), Paris, France, 19-21 October 2015.

3. Lavazza, L.; Morasca, S.; Taibi, D.; Tosi, D. Predicting OSS Trustworthiness on the Basis of Elementary Code Assessment. In Proceedings of the ACM/IEEE 4th Empirical Software Engineering and Measurement conference (ESEM 2010), Bolzano, Italy, 16-17 September 2010.

4. Tosi, D.; Chiappa, M. Understanding the Geographical Spread of COVID-19 in relation with Goods Regional Routes and Governmental Decrees: The Lombardy Region Case Study. Int. J. SN Comput. Sci. 2020, 2, 203. [CrossRef] [PubMed]

5. Tosi, D.; Campi, A. How Data Analytics and Big Data can Help Scientists in Managing COVID-19 Diffusion: A Model to Predict the COVID-19 Diffusion in Italy and Lombardy Region. Int. J. Med. Internet Res. 2020, 22, e21081. [CrossRef] [PubMed]

6. Tosi, D.; Verde, A. Clarification of Misleading Perceptions of COVID-19 Fatality and Testing Rates in Italy: Data Analysis. Int. J. Med. Internet Res. 2020, 22, e19825. [CrossRef] [PubMed] 
7. Rennert, L.; McMahan, C.; Kalbaugh, C.A.; Yang, Y.; Lumsden, B.; Dean, D.; Pekarek, L.; Colenda, C.C. Surveillance-based informative testing for detection and containment of SARS-CoV-2 outbreaks on a public university campus: An observational and modelling study. Lancet Child Adolesc. Health 2021. [CrossRef]

8. Levinson, M.; Cevik, M.; Lipsitch, M. Reopening Primary Schools during the Pandemic. N. Engl. J. Med. 2020, 383, 981-985. [CrossRef] [PubMed]

9. Ismail, S.A.; Saliba, V.; Bernal, J.L.; Ramsay, M.E.; Ladhani, S.N. SARS-CoV-2 infection and transmission in educational settings: A prospective, cross-sectional analysis of infection clusters and outbreaks in England. Lancet Infect. Dis. 2021, 21, 344-353. [CrossRef]

10. Di Domenico, L.; Pullano, G.; Sabbatini, C.E.; Boëlle, P.; Colizza, V. Modelling safe protocols for reopening schools during the COVID-19 pandemic in France. Nat. Commun. 2021, 12, 1073. [CrossRef] [PubMed]

11. Panovska-Griffiths, J.; Kerr, C.C.; Stuart, R.M.; di Domenico, L.; Pierre-Yves, B.; Vittoria, C. Determining the optimal strategy for reopening schools, the impact of test and trace interventions, and the risk of occurrence of a second COVID-19 epidemic wave in the UK: A modelling study. Lancet Child Adolesc. Health 2020, 4, 817-827. [CrossRef]

12. Bayham, J.; Fenichel, E.P. Impact of school closures for COVID-19 on the US health-care workforce and net mortality: A modelling study. Lancet Public Health 2020, 5, e271-e278. [CrossRef]

13. Haug, N.; Geyrhofer, L.; Londei, A.; Dervic, E.; Desvars-Larrive, A.; Loreto, V.; Pinior, B.; Thurner, S.; Klimek, P. Ranking the effectiveness of worldwide COVID-19 government interventions. Nat. Hum. Behav. 2020, 4, 1303-1312. [CrossRef] [PubMed]

14. Brauner, J.M.; Mindermann, S.; Sharma, M.; Johnston, D.; Salvatier, J.; Gavenčiak, T.; Stephenson, A.B.; Leech, G.; Altman, G.; Mikulik, V.; et al. Inferring the effectiveness of government interventions against COVID-19. Sci. Dic. 2020, 371 , eabd9338.

15. Ferretti, A. Schools and COVID19 Cases in Italy. Available online: https:/ / www.ilfattoquotidiano.it/blog/aferretti/ (accessed on 27 April 2021).

16. Schools and Positive Cases in Lazio Region. Available online: https://roma.repubblica.it/cronaca/2021/03/16/news/ scuola_coronavirus_focolai_covid_zona_rossa_roma_lazio-292442424/?ref=fbplrm\&fbclid=IwAR1r1yvwvyc57qYug1ZXi5 -ewDCvXpRz7i_tmM9WIP72O3pFDsT9jrog4M (accessed on 27 April 2021).

17. Belgium Prime Minister Press Conference (19/03/2021). Available online: https://www.brusselstimes.com/news/belgium-allnews / 160897 / belgium-consultative-committee-alexander-de-croo-frank-vandenbroucke-outdoor-plan-events-amusementparks-youth-camps-trains-holiday / (accessed on 27 April 2021).

18. Press Release COVID19 Cases at Italian Schools. Available online: https://www.facebook.com/prediremegliochecurare (accessed on 27 April 2021).

19. Kar, S.K.; Yasir Arafat, S.M.; Kabir, R.; Sharma, P.; Saxena, S.K. Coping with Mental Health Challenges During COVID-19. In Medical Virology: From Pathogenesis to Disease Control; Saxena, S., Ed.; Coronavirus Disease 2019 (COVID-19); Springer: Singapore, 2020. [CrossRef]

20. Pillai, S.; Siddika, N.; Hoque Apu, E.; Kabir, R. COVID-19: Situation of European Countries so Far. Arch. Med. Res. 2020, 51, 723-725. [CrossRef] [PubMed]

21. Vinnakota, D.; Parsa, A.D.; Arafat, S.Y.; Sivasubramanian, M.; Kabir, R. COVID-19 and risk factors of suicidal behaviour in UK: A content analysis of online newspaper. J. Affect. Disord. Rep. 2021, 4, 100142. [CrossRef]

22. MIUR Dataset of COVID Infection in Italian Schools. Available online: https://drive.google.com/file/d/1bZuV-UmLd40kxBof1 iaPJEJHrlNPUIw3/view (accessed on 27 April 2021).

23. Dashboard National, Regional and Provincial Curves. Available online: www.covid19-italy.it (accessed on 27 April 2021).

24. Official Opendata COVID19 Italy. Department Civil Protection. Available online: https://github.com/pcm-dpc/COVID-19 (accessed on 27 April 2021).

25. Ordinanza Scuole Regione Lombardia. Available online: https://www.regione.lombardia.it/wps/portal/istituzionale/HP/ coronavirus / misure (accessed on 27 April 2021).

26. Ordinanza Scuole Regione Campania. Available online: http://www.regioni.it/newsletter/n-3930/del-16-10-2020 / campaniaordinanza-di-chiusura-scuole-e-universita-fino-al-30-ottobre-21783/ (accessed on 27 April 2021).

27. Covid19 Google Community Mobility Report. Available online: https://www.google.com/covid19/mobility/ (accessed on 27 April 2021).

28. Wallinga, J.; Teunis, P. Different epidemic curves for severe acute respiratory syndrome reveal similar impacts of control measures. Am. J. Epidemiol. 2004, 160, 509-516. [CrossRef] [PubMed] 